\title{
A Comparative Expected Value Analysis Study to Determine If the Economic Benefits of the Most Commonly Prescribed Prescription and Non-Prescription Drugs in the United States Provide Economic Value
}

\author{
S. Eric Anderson 1 , Jim Pinder ${ }^{2}$, Armond Manassian ${ }^{3}$, Reet Singh ${ }^{4}$ \\ ${ }_{1,2,3,4} \mathrm{La}$ Sierra University, Riverside, California
}

\begin{abstract}
It was found that anti-biotics, aspirin, bisphosphonates, blood pressure lowering medications, statins, medications treating depression, diabetes, sexual dysfunction and the poly-pill provided economic value, while medications to treat Alzheimer's, cancer, multiple sclerosis and Clopidogrel were not found to have provided economic value. The current evidence is insufficient to determine if weight loss medication provides economic value or not.
\end{abstract}

KEYWORDS: Economic value, anti-biotics, aspirin, bisphosphonates, blood pressure, statins, diabetes, sexual dysfunction, polypill, Alzheimer's, cancer, multiple sclerosis, Clopidogrel, weight-loss.

\section{INTRODUCTION}

In the United States, the total amount of money spent on medications was approximately 511 billion dollars in 2019. Spending increased each year between 2012 and 2019, rising by a total of almost 200 billion dollars during that seven-year period. Brand name drugs accounted for 80 percent of the total medicine sales in 2019 (Mikulic, 2020). Almost one in two people in the United States (or $46 \%$ of the population) used one or more prescription drugs in the last month between the years 2015-2016 (Pesce, 2019). It is estimated that in 2019, 4.38 billion prescriptions will be filled throughout the United States at retail pharmacies. By 2025, that number will go up to 4.98 billion, an increase of almost 14 percent (Statista, 2021). From 2019 to 2020, pharmaceutical expenditures grew by 4.9 percent and utilization increased by 2.9 percent. The top drugs in 2020 were Adalimumab (reduces joint swelling), apixaban (prevents strokes), and insulin glargine (long-acting insulin). The study predicts specialty and cancer drugs will drive future spending increases. It was predicted that in 2021 prescription drug spending would increase by four to six percent (Tichy, 2021). The median out-of-pocket dollars Americans spent on retail medications fell from \$1,369 in 2009 to $\$ 945$ in 2018 (Carroll, 2020). There are many reasons a prescription medication is not effective at treating a disease or disorder. These reasons include wrong drug or dosage, incorrect diagnosis, adverse reaction, or lack of patient adherence. The drug may also be a fake or have poor bioavailability (Figueras, 2003). With FDA approval, a prescription medication can be reclassified as over the counter. Each dollar spent on OTC medication save the health care system \$7.20 (Health Day, 2019). In the United States prescription medicine is on average 2.56 times higher than in other countries (Mulcahy, 2021). The United States consumes 75 percent of the world's prescription drugs (Wilkinson 2015). The top 10 most commonly used prescription drugs are: Vicodin; Simvastatin; Lisinopril; Levothyroxine; Azithromycin; Metformin; Lipitorl; Amlodipine; Amoxicillin and Hydrochlorothiazide (Ogbru, 2021). Drugs like ibuprofen and other painkillers are over-the-counter (OTC) in other countries, but are both prescription and OTC in the United States (Pharmaceutical Updates, 2021). The average outofpocket cost for adults is $\$ 177$ and older people pay $\$ 456$ on average (AMA, 2020). The drug prices in the United States are 256 percent higher compared to other countries (McGrail, 2021). Retail prescription drugs account for 10 percent of total National Health Expenditures in the United States. However, including pharmaceuticals consumed in other health care settings or in hospitals pushes the United States drug spending as a share of NHE, to 17 percent (DHHS, 2016).

A comparative expected value analysis study is a straight forward method to determine the financial viability of investing healthcare dollars in prescription drugs for a range of illnesses or disorders. This approach can be utilized to analyse the likelihood that identified prescription drugs will result in a cost reduction or savings that exceeds the cost to purchase the prescription drugs.

\section{RESULTS}

Alzheimer's - None of the pharmacologic treatments (medications) available today for Alzheimer's dementia slow or stop the damage and destruction of neurons that cause Alzheimer's symptoms and make the disease fatal (Alzheimer's Association, 2020). Antipsychotics may be prescribed to treat hallucinations, aggression and agitation 


\section{"A Comparative Expected Value Analysis Study to Determine If the Economic Benefits of the Most Commonly Prescribed Prescription and Non-Prescription Drugs in the United States Provide Economic Value"}

(Ralph et al, 2018). However, research has shown that some antipsychotics are associated with an increased risk of stroke and death in individuals with dementia (Maust et al, 2015). A recent review and analysis of non

pharmacologic treatments for agitation and aggression in people with dementia concluded that non pharmacologic interventions seemed to be more effective than pharmacologic interventions for reducing aggression and agitation (Watt et al, 2019).

Exercise has a positive effect on overall cognitive function and may slow the rate of cognitive decline in people with Alzheimer's dementia (Farina, 2014). Cognitive stimulation does have beneficial effects on cognitive function and some aspects of well being in people with Alzheimer's dementia (Aguirre et al, 2013). The World Health Organization (2019) strongly recommends physical activity, quitting smoking, and managing hypertension and diabetes to reduce the risk of cognitive decline and dementia. Physical activity appears to be effective in reducing risk (Ogino et al, 2019). In addition to physical activity, emerging evidence suggests that consuming a heart healthy diet may be associated with reduced dementia risk (BarbergerGateau, 2007). A systematic review of the use of supplements, including (but not limited to) vitamins $\mathrm{C}, \mathrm{D}$ and $\mathrm{E}$, omega 3 fatty acids, and ginkgo biloba, found little to no benefit in preventing cognitive decline, MCI or Alzheimer's dementia (Butler et al, 2018).

Antibiotics - The value of antibiotics priced at around \$10 is highly favorable in terms of value when compared with many other interventions. Antibiotics to treat (full cure) a lifethreatening or limb-threatening pathogen usually cost between \$2,000 and \$3,000 (McKellar et al, 2014). More than 150 million prescriptions are written for antibiotics in the United States each year and bacteria are starting to adapt to the drugs and are becoming harder to kill (WebMD, 2020). The economic burden of antibiotic resistance costs the United States up to $\$ 20$ billion directly, and up to $\$ 35$ billion indirect each year (CDC, 2013), which comes at a per person cost of around $\$ 133$ ( $\$ 20$ billion / 150 million prescriptions). At least 30 percent of antibiotics prescribed in the United States are unnecessary, according to new data published today in the Journal of the American Medical Association (JAMA) by the Centers for Disease Control and Prevention (CDC), in collaboration with Pew Charitable Trusts and other public health and medical experts (CDC, 2016). Even though a third of the antibiotic prescriptions are unnecessary they still provide value since it only reduces the overall cost effectiveness and doesn't eliminate it.

Aspirin - One heart attack or stroke will be avoided for every fifty people with heart disease taking aspirin

(Stafford, 2017). Aspirin combined with blood pressure medication further reduces the risk of a stroke by preventing blood platelets from forming a clot and provide additional economic value. The cost of a stroke ranged from $\$ 20,396 \pm$
$\$ 23,256$ (Wang et al, 2014) and the expected cost to reduce a stroke was $\$ 2,500(\$ 50 / .02)$.

Bisphosphonates - One hundred post-menopausal women would have to take bisphosphonates in order to avoid a single hip fracture (1\%) per year (Wells et al, 2008). The overall rate of non-vertebral fracture was 6 percent in the bisphosphonate group and 9.6 percent in the placebo group (Byun, et al, 2017). Generic Fosamax costs roughly $\$ 100$ to $\$ 200$ per year, which would place the cost of preventing a hip fracture at $\$ 15,000$ (\$150/1\%). According to MD Save, the average cost for a hip replacement in the United States is around \$32,000, which would provide a net benefit of $\$ 17,000(\$ 32,000-\$ 15,000)$. A pharma-economic model based on individual long-term risks of fracture improves the selection of postmenopausal women for cost-effective treatment with bisphosphonates (van Staa et al, 2007).

Blood Pressure - Blood pressure medicines designed to reduce the risk of heart disease, heart attack and stroke cost around \$50 per year (CDC, 2020). According to the Agency for Healthcare Research and Quality (Steiner et al, 2012), the average length of hospitalization and related costs for heart attack patients is 5.3 days at $\$ 21,500$ per stay. Therefore, just one heart attack for every $430(\$ 21,500 / \$ 50)$ patients taking blood pressure medication would need to be averted in order for the medication to provide economic value. However, it should be realized that some patients with mildly elevated blood pressure may not benefit from taking blood pressurelowering medications since these medications can lower a patient's blood pressure too much, causing falls and other preventable accidents.

Cancer - Cancer drugs account for approximately 10 percent of the total prescription drug market (Quintiles IMS Institute, 2017) and new cancer treatments are now routinely priced at more than $\$ 100,000$ per year of treatment (Light et al, 2013). The list price for drugs affects cost-effectiveness calculations. Using the list price of cancer drugs invariably makes newer drugs appear less valuable, even though health insurers frequently pay prices well below the list price of oncology drugs (Polite et al, 2014). Drugs for which the incremental costs per quality adjusted life year (QALY) gained exceed a certain threshold, often $\$ 100,000$ per QALY, are deemed to be of low value (Fonseca et al, 2018). Investigators estimate that 9 in every 10 drugs fail at some point in the research and development process (DiMasi, 2013) resulting with estimated costs of drug development (including failed therapies) of over $\$ 2$ billion per marketed drug (DiMasi 2003). Critics of this view, point to the fact that many marketed therapies received large, initial support from federal sources such as the National Institutes of Health (Kesselheim et al, 2015). It was also pointed out that the pharmaceutical industry spends more on marketing as than research and development earns profits in excess of other industries (Anderson, 2014) and that two- 


\section{"A Comparative Expected Value Analysis Study to Determine If the Economic Benefits of the Most Commonly Prescribed Prescription and Non-Prescription Drugs in the United States Provide Economic Value"}

thirds of drugs brought to market have a net present value of returns (lifetime sales) below the cost of development (DiMasi et al, 2003). Reductions in drug prices will lead to reductions in innovation (Scherer, 2004). Lower prices may increase access to cancer therapies, improve cancer outcomes, and possibly lower cancer spending today, but may reduce access to innovative therapies and the possibility of better cancer outcomes moving forward (Acemoglu, 2004). Despite the United States outspending other developed nations, outcomes in terms of preventable deaths and years of life lost to malignant disease were not better and in some cases were significantly worse (Cylus, 2007). In 2005, lower Medicare part B reimbursement for chemotherapy resulted in a dramatic drop in usage after the January 2005 payment change (Jacobson et al, 2010).

Cholesterol (Statins) - United States National survey data suggest statin therapy reduced low-density lipoprotein levels by 18.8 percent, which results in 40,000 fewer deaths, 60,000 fewer hospitalizations for heart attacks and 22,000 fewer hospitalizations for strokes in 2008 (Grabowski, 2012). Statin therapy was also associated with a 27 percent reduction in cardiovascular healthcare costs per patient versus placebo (Gotto et al, 2000). An analysis of analysis of 18 trials, including 56,934 patients primarily without cardiovascular disease, demonstrated statins conferred a relative risk reduction (RRR) in all-cause mortality by 14 percent and in stroke by 22 percent (Cochrane, 2013). From 1987 to 2008, the estimated aggregate social value of statins was estimated to be $\$ 1,252$ trillion that cost an estimated 947.4 billion (Grabowski, 2012).

Depression - Antidepressants improved symptoms in about 20 out of 100 (NCBI, 2015) and a generic antidepressant can be purchased for as little as $\$ 4$ per month or $\$ 48$ per year (Westra, 2010) Research shows that psychotherapy for depression is as effective as antidepressant medications during the treatment period (Westra, 2010). However, seeing a psychotherapist costs over $\$ 200$ per session, so a six session treatment program spread over three months would cost around $\$ 1,200$, which is about 24 times the annual cost for generic antidepressant medication. Pfeiffer, Heisler, Piette, Rogers and Valenstein (2010) reported no significant difference in depression outcomes between those randomized in a peer support intervention versus cognitive therapy. The cost to join a weekly support group can cost as little as $\$ 15$ per week (\$60 per month) or $\$ 180$ (three months). Goyal (2014) reported that mindfulness meditation may be just as effective as medication when it comes to the treatment of depression, and no third-party cost is associated with engaging in mindfulness. Likewise, exercise enhances the action of endorphins circulating throughout the body improving natural immunity and is as effective at reducing mild depression as antidepressant medications (Harvard Health Letter, 2013). The amount spent to treat depressive disorders in the United States is $\$ 71$ billion (Dieleman, Baral \& Birger, 2016), and 16.2 million adults in the United States have at least one major depressive episode in a given year (Koskie, 2018). Therefore, the cost per person (CPP) for depressive disorders in the United States is $\$ 4,382$ per person (\$71 billion / 16.2 million). It was found that exercise and meditation which cost nothing provided the most value treating mild depression followed by medication, which had an annual payback period (APP) of .05.

\begin{tabular}{|c|c|c|c|c|c|c|}
\hline $\begin{array}{c}\text { Progra } \\
\text { ms }\end{array}$ & SR & Cost & $\begin{array}{c}\text { Cost/ } \\
\text { SR }\end{array}$ & CPP & BPP & $\begin{array}{c}\text { AP } \\
\text { P }\end{array}$ \\
\hline Exercise & $20 \%$ & $\$ 0$ & $\$ 0$ & $\$ 4,38$ & $\$ 438$ & .00 \\
2 & 2 & \\
\hline $\begin{array}{c}\text { Meditati } \\
\text { on }\end{array}$ & $20 \%$ & $\$ 0$ & $\$ 0$ & $\$ 4,38$ & $\$ 438$ & .00 \\
\hline $\begin{array}{c}\text { Medicat } \\
\text { ion }\end{array}$ & $20 \%$ & $\$ 48$ & $\$ 240$ & $\$ 4,38$ & $\$ 414$ & .05 \\
\hline $\begin{array}{c}\text { Groups } \\
\text { Therapy }\end{array}$ & $20 \%$ & $\$ 180$ & $\$ 900$ & $\$ 4,38$ & $\$ 348$ & .20 \\
2 & $\$ 120$ & $\$ 6,00$ & $\$ 4,38$ & $\$ 138$ & 1.37 \\
\hline
\end{tabular}

Diabetes - The age-gender weighted average of the lifetime medical costs for treating type 3 diabetes and diabetes complications was $\$ 85,200$, of which $53 \%$ was due to treating diabetic complications (Zhou, 2013). A decreased A1C of $1 \%$ or more was associated with lower total healthcare costs (\$685-\$950 less per year) than those without an improvement in the A1C value (Wagner, et al, 2001). There are no pharmacologic treatments (medication) that are available that been proven to stop or cure Diabetes, but with the right medication the disease can be controlled (American Diabetes Association, 2018). It costs about $\$ 740$ a year to keep the disease under control (Nguyen et al, 2020). The most effective treatment to reduce costs would be exercise, diet and insulin therapy. Exercise has a positive effect on the overall treatment and has shown an increase to the overall body health when diagnosed with diabetes as the healthier you are it becomes easier to manage your disease, monitoring your blood sugar does have a beneficial effect on the wellbeing in people with diabetes (Mayo Clinic 2021). Exercise has a positive effect on the overall treatment and has shown an increase to the overall body health when diagnosed with diabetes as the healthier you are it becomes easier to manage your disease, monitoring your blood sugar does have a beneficial effect on the well-being in people with diabetes (WebMD, 2019). In addition, to physical activity adding a healthy diet can be helpful as well (Nall, 2020). Physical activity is effective in increasing the body's sensitivity to insulin, which helps control the blood sugar elevations (Stoppler, 2020). The combined impact of diet and exercise provide more value since they are deemed to be more effective than medication alone. 


\section{"A Comparative Expected Value Analysis Study to Determine If the Economic Benefits of the Most Commonly Prescribed Prescription and Non-Prescription Drugs in the United States Provide Economic Value"}

Multiple Sclerosis - Cost-effectiveness thresholds for most drugs treating multiple sclerosis substantially exceeded the commonly accepted $\$ 100,000-\$ 150,000$ per quality adjusted life year threshold, even when using prices that account for typical discounts and rebates that may apply in real-world practice (ICER, 2017). ICER's analyses found that the prices of a majority of the drugs reviewed would need to be discounted anywhere from 25 percent to 94 percent, depending on the drug, in order to meet commonly accepted thresholds for cost-effectiveness (ICER, 2017).

Clopidogrel - Clopidogrel is a blood thinner that helps in preventing strokes, heart attacks and other heart diseases and has a success rate of 20 percent (Harvard, 2014). It can be given to people who have Acute Coronary Syndrome (ACS); have Peripheral Artery Disease (PAD) and have had a heart attack or stroke in the past (Davydovskaya \& Slowiczek, 2019). The cost of this brand name prescription drug is an average of $\$ 61.28$ (Goodrx, 2021). The average price of an oral tablet of $75 \mathrm{mg}$ is $\$ 160$ per 15 tablets on Drugs.com (2021). Being a blood thinner there are common side effects of this tablet, like easy bleeding, stomach ache, diarrhea and constipation. The duration and the strength of the dose are decided by the doctor upon examination of the disease and its type. Clopidogrel is also an antiplatelet drug, which means that if one is aware of being allergic to such kinds of drugs then they need to make sure to tell their doctor (WebMD, 2020). Even though Clopidogrel is a commonly prescribed disease it is not cost-effective. A recent study journal has proved that generic Clopidogrel is much more cost effective than Clopidogrel. Using the generic version would help reduce healthcare costs to a point (Ko et al., 2018). Through the method of clinical trials and registries their results have shown that a $300 \mathrm{mg}$ dose (administered) is effective in treating ACS (acute coronary syndrome) (Zuzana \& Kala, 2008).

Poly-Pill - A daily "poly-pill" consisting of three antihypertensive drugs, a statin, and aspirin to prevent cardiovascular disease was found to reduce the lifetime risk of cardiovascular disease by 15 percent in women and by 21 percent in men if the poly-pill were used by people with a risk of cardiovascular disease equal to or greater than 15 percent over ten years. Attaining this goal would require treating 26 percent of the population at a cost of \$34-\$36 per qualityadjusted life-year. Offering the poly-pill to women at high risk and to men age fifty-five or older would be the best approach and would yield acceptable incremental cost-effectiveness ratios. The poly-pill would be very cost-effective even in the country with the lowest gross national income in our study. However, policy makers must weigh the value of intervention with the polypill against other interventions, as well as their country's willingness and ability to pay for the intervention (Bautista, et al, 2013).
Sexual Dysfunction - Generic, sildenafil can cost as little as \$4 per tablet with GoodRx.com. The act of sex is free since legally one can't charge for it and there is evidence that sex improves one's health. Men burned an average of 4 calories a minutes during sex sessions and women burned 3 calories during sex sessions, which can be more fun than running on a treadmill. Men who had sex twice weekly or more had less risk of cardiovascular diseases, like stroke or heart attack, than those who had sex once a month or less (Hall, 2010). Sex boosts the immune system, burns calories, lowers blood pressure, lessens risk of heart attack, may ward off prostate cancer, relaxes, reduces pain and prolongs life (Castleman, 2021).

Weight Loss - The National Center for Health Statistics estimated in 2015-2016 in the United States, 39.8 percent of adults aged 20 and over were obese (including $7.6 \%$ with severe obesity) and that another 31.8 percent were overweight (Fryar, 2018). Approximately $\$ 147$ billion is added medical expenses per year due to obesity in the United States. Therefore, the cost per person (CPP) for one that is obese or the savings in medical expenses would be $\$ 1,429$ per year (Antonelli, Maalouf, Pearle \& Lotan, 2014). It was found that medication provided the most value reducing the prevalence of obesity with an annual payback (APB) of 3.3 years.

The American Society of Plastic Surgeons (2019) reported that the average cost for liposuction in 2014 was $\$ 3,518$. After liposuction, weight gain was reported in $43 \%$ (57\% success rate) of the responders, 79.7 percent would have the procedure again and 86 percent would recommend the procedure to family or friends (Broughton, Horton, Lipschitz, Kenkel, Brown and Rohrich, 2006). Two weekly personal training sessions would cost $\$ 400$ per month or $\$ 4,800$ annually. Those that work with a trainer can expect on average to lose one to two pounds a week and see noticeable results within the first three to six weeks (Arroyo, 2017). McClaran (2003) found that a personal trainer significantly increased clients' physical activity and 60 percent of study participants were successful. The average cost of Lap-Band surgery is about $\$ 3,500$ with insurance and $\$ 15,000$ without insurance (Quinlan, 2019). After 16 years, 62 percent of the 3,227 individuals treated with a laparoscopic adjustable gastric band still had significant weight loss (O’Brien, MacDonald, Anderson, Brennan \& Brown, 2013). All prescription weightloss drugs approved for long-term use produce significant weight loss compared to the placebo (Mayo Clinic, 2018). Studies show that the addition of weight-loss medication to lifestyle changes results in greater weight loss than lifestyle changes alone produce. Over the course of 12 months, one can expect a mean weight loss of 3 to 7 percent of total body weight beyond that achieved with lifestyle changes alone (Mayo Clinic, 2018). Phentermine (Adipex-P) is a popular drug used to decrease appetite that is available in a generic version (Mayo Clinic, 2018). On-line retailers selling the 
Adipex-P quote an average retail price of $\$ 34.33$ with an annual cost of $\$ 411.96$. After stopping weight-loss medication people often gain back some of the weight they lost. However, adopting healthy lifestyle habits may help limit weight gain. The ten-year cost would be $\$ 4,119.60$. Phentermine based on 524 user ratings, was found to be 87 percent effective (Drugs.com, 2019).

\begin{tabular}{|c|c|c|c|c|c|c|}
\hline $\begin{array}{c}\text { Program } \\
\text { s }\end{array}$ & SR & Cost & $\begin{array}{c}\text { Cost/S } \\
\mathbf{R}\end{array}$ & $\mathbf{C P P}$ & $\mathbf{B P P}$ & $\begin{array}{c}\text { AP } \\
\mathbf{P}\end{array}$ \\
\hline Drugs & 87 & $\$ 4,110$ & $\$ 4,724$ & $\$ 1,42$ & - & 3.30 \\
& $\%$ & & & 9 & $\$ 3,29$ & \\
\hline $\begin{array}{c}\text { Liposucti } \\
\text { on }\end{array}$ & 57 & $\$ 3,518$ & $\$ 6,172$ & $\$ 1,42$ & - & 4.31 \\
& $\%$ & & & 9 & $\$ 4,74$ & \\
\hline Trainer & 60 & $\$ 4,800$ & $\$ 8,000$ & $\$ 1,42$ & - & 5.59 \\
& $\%$ & & & 9 & $\$ 6,57$ & \\
\hline Lap Band & 62 & $\$ 15,00$ & $\$ 24,19$ & $\$ 1,42$ & - & 22.7 \\
& $\%$ & 0 & 3 & 9 & $\$ 2276$ & 6 \\
& & & & & 4 & \\
\hline
\end{tabular}

There is currently not a consensus on whether or not a 3.3 year payback period for weight loss drugs provides economic value or not.

\section{SUMMARY}

A comparative expected value analysis study was used to determine if the healthcare dollars invested in the most commonly used prescription results in a net cost savings.

The amount of data available for each condition varied significantly. However, the analysis provides a clear snapshot of the likely cost to treat disease with prescription drugs.

It was found that anti-biotics, aspirin, bisphosphonates, blood pressure lowering medications, statins, medications treating depression, diabetes, sexual dysfunction and the poly-pill provided economic value, while medications to treat Alzheimer's, cancer, multiple sclerosis and Clopidogrel were not found to have provided economic value. However, generic Clopidogrel was found to have provided value. The current evidence is insufficient to determine if weight loss medication provides economic value or not. Currently, none of the medications prescribed to slow or stop the damage and destruction of neurons that cause Alzheimer's symptoms and make the disease fatal provide value (Alzheimer's Association, 2020).

\section{CONCLUSION}

The results of this study may potentially impact a variety of stakeholders who stand to benefit from the findings. A primary group would be individual patients who make decisions to undergo early screening and treatment based on financial considerations. Private insurance companies and hospitals constitute another group of stakeholders as they are major players on the supply side. The cost effectiveness of these services is a major factor in determining the extent of their availability. It's important to note that politicians who deliberate public policy formulation regarding national healthcare issues would be another important category of stakeholders. The Congressional Budget Office uses the comparative expected value approach to determine the cost effectiveness of prescription drugs as they develop healthcare policy. The methodology employed in this study is in line with those employed in similar studies within the literature.

\section{REFERENCES}

1. Acemoglu D, Linn J, Market size in innovation: theory and evidence from the pharmaceutical industry. Q J Econ. 2004;119 (3): 1049-1090.

2. Aguirre E, Woods RT, Spector A, Orrell M, Cognitive stimulation for dementia: A systematic review of the evidence of effectiveness from randomized controlled trials. Aging Res Rev 2013:12(1):253-62.

3. Alzheimer's Association Report, 2020 Alzheimer's disease facts and figures. Alzheimers Dement. 2020;16: 391- 460.

4. American Diabetes Association, Screening for Diabetes and Prediabetes should be cost-saving in patients at high risk, American Diabetes Association, 2018.

5. American Society of Plastic Surgeons, Plastic Surgery Statistical Report, 2019

6. Anderson R, Pharmaceutical industry gets high on fat profits. BBC News, 2014, November 6 .

7. Arroyo D, How soon can I see results from a personal trainer? Live Strong, 2017, Dec 29.

8. Barberger-Gateau P, Raffaitin C, Letenneur L, Berr C, Tzourio C, Dartigues JF, Dietary patterns and risk of dementia: The Three-City Cohort Study, Neurology 2007; 69(20):1921-30.

9. Broughton G, Horton B, Lipschitz A, Kenkel JM, Brown SA, Rohrich RJ, Lifestyle outcomes, satisfaction, and attitudes of patients after liposuction: A Dallas experience. Plast Reconstru Surg, 2006, May; 117 (6):1738-49.

10. Butler M, Nelson VA, Davila H, Ratner E, Fink HA, Hemmy LS, Over-the-counter supplement interventions to prevent cognitive decline, mild cognitive impairment and clinical Alzheimer-type dementia. Ann Inter Med 2018; 168-52-62.

11. Bautista LE, Vera-Cala LM, Ferrante D, Herrera VM, A polypill aimed at preventing cardiovascular disease could prove highly cost-effective for use in Latin America, Health Affairs, January 2013, 32(1).

12. Byun JH, Jang $\mathrm{S}$, Lee $\mathrm{S}$, et al. The efficacy of Bisphosphonates for prevention of osteoporotic 
fracture: An update meta-analysis. J Bone Metab. 2017;24 (1):37-49.

13. Caldeira D, Fernandes RM, Costa J, David C, Sampaio C, Ferreira J, Branded versus generic clopidogrel in cardiovascular diseases: A systematic review. Retrieved March 03, 2021

14. Carroll W, Miller G, Hill S, Statistical Brief \#532: Out-of-Pocket Spending for Retail Prescribed Drugs by Age and Type of Prescription Drug Coverage, 2009 to 2018. 2020, December

15. Castleman M, Eight reasons sex improves your health, AARP Report, 2021

16. Centers for Disease Control and Prevention, Antibiotic resistance threats in the United States, 2016

17. Cochrane, Statins for the primary prevention of cardiovascular disease. Cochrane Database System Review, 2013 Jan 31;

18. Cylus J, Anderson GF. Multinational Comparisons of Health Systems Data, 2006. New York: The Commonwealth Fund; April 2007.

19. Davydovskaya Y, Slowiczek L, Plavix: Side effects, Uses, dosage, and more. Medical News Today, 2019, December 9.

20. Dieleman JL, Baral R, Birger M, U.S. Spending on personal health care and public health, 1996-2013. JAMA. 2016, doi:10.1001/jama.2016.16885.

21. DiMasi JA, Reichert JM, Feldman L, Malins A. Clinical approval success rates for investigational cancer drugs. Clin Pharmacol Ther. 2013, 94(3):329-335.

22. DiMasi JA, Hansen RW, Grabowski HG. The price of innovation: new estimates of drug development costs. J Health Econ. 2003; 22(2):151-185. 18.

23. Drugs.com, Plavix prices, coupons and patient assistance programs. Retrieved March 02, 2021.

24. Drugs.com, User Reviews for Phentermine, 2019.

25. Farina N, Rusted J, Tabet N, The effect of exercise interventions on cognitive outcome in Alzheimer's disease: A systematic review. Int Psychogeriatr 2014, 26(1):9-18.

26. Ferry R, Stoppler MC, Diabetes, Medicine Net, 2020.

27. Figueras A, Laporte J, Failures of the therapeutic chain as a cause of drug ineffectiveness Promotion, misinformation and economics works better than needs, BMJ, 2003, 326: 895

28. Fonseca R, Peneva D, Clancy Z, Abouzaid S, and Anupam BJ, The Importance of Economic Tradeoffs in Cancer Drug Pricing, 2018.

29. Frappier J, Toupin I, Levy JL, Aubertin-Leheudre M, Karelis AD, Energy Expenditure during sexual activity in young health couples, Plus One, 2013, October 24.
30. Fryar CD, Prevalence of overweight, obesity and severe obesity among adults aged 20 and over, United States, 1960-1962 through 2015 - 2016, Health E-Stats, National Center for Health Statistics, Division of Health Interview Statistics, 2018.

31. Goodrx, Plavix prices, coupons \& savings tips. Retrieved March 02, 2021.

32. Gotto AM, Boccuzzi SJ, Cook JR, Effect of lovastatin on cardiovascular resource utililzation and costs in the Air Force/Texas Coronoary Atherosclerosis Prevention Study, AM J Cardiol, 2000, 86:1176-1181.

33. Goyal M, Meditation programs for psychological stress and well-being: A systematic Review and Meta-analysis, JAMA Intern Med, 2014, 174(3):357-368 doi:10.1001/jamainternmed.2013.13018.

34. Grabowski DC (2012) The large social value resulting from use of statins warrants steps to improve adherence and broaden treatment, Health Affairs, 31: 10, 2276-2285.

35. Hall SA, Shackelton R, Rosen RC, Araujo AB, Sexual activity erectile dysfunction and incident cardiovascular events, Am J Cardiol, 2010, Jan 15, 105(2): 192-197.

36. Harvard Health, Exercise is an all-natural treatment to fight depression - Exercise is as effective as drugs in some cases, Harvard Health Publishing, 2013, August.

37. Harvard Health, Who needs Plavix. Harvard Health Publishing, 2014, March.

38. Health Day, Over-the-Counter Meds Save Health Care System Money, Medical Xpress, 2019, April 2

39. Health Policy Institute, Prescription Drugs, Georgetown University, 2021

40. Institute for Clinical and Economic Review (ICER), Evidence report assessing the comparative clinical effectiveness and value of 15 diseasemodifying therapies (DMTs) for treatment of relapsing-remitting and primary-progressive multiple sclerosis. California Technology Assessment Forum (CTAF), 2017, February 16.

41. Jacobson M, Earle CC, Price M, Newhouse JP. How Medicare's payment cuts for cancer chemotherapy changed patterns of treatment, Health Aff, 2010, 29:1391-1399.

42. Kesselheim AS, Tan YT, Avorn J. The roles of academia, rare diseases, and repurposing in the development of the most transformative drugs. Health Aff, 2015, 34(2):286-293.

43. Ko DT, Krumholz, HM, Tu JV, Austin PC, Stukel TA. Koh M, Jackevicius C, Clinical outcomes OF 
PLAVIX and Generic clopidogrel for patients hospitalized with an Acute CORONARY Syndrome. Circulation: Cardiovascular Quality and Outcomes, 2018, 11(3).

44. Koskie B, Depression, facts, statistics and you, Healthline, 2018, June 29.

45. Light DW, Kantarjian H. Market spiral pricing of cancer drugs. Cancer. 2013, 119(22):3900-3902.

46. Maust DT, Kim HM, Seyfried LS, Chiang C, Kavanagh J, Schneider LS, Antipsychotics, other psychotropics and the risk of death in patients with dementia: number needed to harm. JAMA Psychiatry 2015, 72:438-45.

47. Mayo Clinic, The importance of economic tradeoffs in cancer drug pricing, Mayo Clin Proc, August 2018;93(8):976-979

48. Nguyen A, Mui K, Guilliford A, The staggering true cost of diabetes, Mayo Foundation for Medical Education and Research, 2020, October.

49. Mayo Clinic Staff (2018). Prescription weight-loss drugs - Examine the pros and cons of medication to treat obesity. Mayo Clinic, September 18.

50. McClaran SR, The effectiveness of personal training on changing attitudes towards physical activity, Journal of Sports Science and Medicine, 2003, 2, 10-14.

51. McGrail S, US Prescription Drug Prices $256 \%$ Higher Than Other Countries, Pharma News Intelligence, 2021, Feb 3

52. McKellar MR, Chernew ME, Fendrick AM, The Economics of Resistant Pathogens and Antiobic innovation, 2014, April 23.

53. Mikulic M, United States total expenditure on medicine, 2002-2019, 2020

54. Mulcahy A, Prescription drug prices in the United States are 2.56 times those in other countries, Rand, 2021, January 28

55. Nall R, Diabetes: Symptoms, treatment and early diagnosis." Medical News Today, Medi Lexicon International, 2020.

56. NCBI, Depression: How effective are antidepressants? NCBI Report, 2015, January.

57. O’Brien PE, MacDonald L, Anderson M, Brennan L, \& Brown WA, Long-term outcomes after bariatric surgery: fifteen-year follow-up of adjustable gastric banding and a systematic review of the bariatric surgical literature, Ann Surg, 2013, 257(1):87-94.

58. Ogbru O, Top ten prescribed drugs in the United States, Medicine Net, 2021

59. Ogina E, Manly JJ, Schupf N, Mayeux R, Gu Y, Current and past leisure time physical activity in relation to risk of Alzheimer's disease in older adults. Alzheimers Dement, 2019, 15(12):16031611.

60. Pesce N, Almost half of Americans have used prescription drugs in the past month, Market Watch, 2019, May 8

61. Pfeiffer, P.N., Heisler, M., Piette, J.D., Rogers, M., \& Valenstein, M. (2010) Efficacy of peer support interventions for depression: A meta-analysis, Gen Hosp Psychiatry, Jan-Feb; 33(1): 29-36.

62. Pharmaceutical Updates, Over-the-counter (OTC) Drugs and Different Countries Regulation, 2021

63. Polite BN, Ward JC, Cox JV, et al. Payment for oncolytics in the United States: a history of buy and bill and proposals for reform. J Oncol Pract. 2014; 10 (6):357- 362

64. Quinlan J, LAP-BAND Surgery Cost in 2018 Starts at \$3,500, Bariatric surgery source, 2019, March 7

65. Quintiles IMS Institute. Medicines Use and Spending in the U.S.: A Review of 2016 and Outlook to 2021, IMS Institute, 2017.

66. Ralph SJ, Espinet AJ, Increased all-cause mortality by antipsychotic drugs: Updated review and metaanalysis in dementia and general menetal healthcare. J Alzheimers Dis Rep 2018, 2:1-26

67. Scherer FM. The pharmaceutical industrydprices and progress. N Engl J Med. 2004, 351(9):927932.

68. Stafford R, Side effects may hamper many blood pressure medications, Scope, 2017, October 19.

69. Statista, Total Number of retail prescriptions filled annually in the United States 2013-2025, 2021, February 4

70. Statista, Total nominal spending on medicines in the U.S. from 2002 to 2019, Statista.com, 2021

71. Steiner C, Barrett M, Weiss A. HCUP Projections: Cardiovascular/Cerebrovascular Conditions and Procedures 2001 to 2012. 2012. HCUP Projections Report \# 2012-02. ONLINE July 10, 2012. U.S. Agency for Healthcare Research and Quality

72. van Staa TP, Kanis JA, Geusens P, Boonen A, Leufkens HG, Cooper C. The cost-effectiveness of bisphosphonates in postmenopausal women based on individual long-term fracture risks. Value Health, 2007, Sep-Oct, 10(5):348-57.

73. Tichy EM, Hoffman J M, Suda KJ, Rim MH, Tadrous M, PharmD, Cuellar S, Clark JS, Wiest MD, Matusiak LM, Schumock GT, National trends in prescription drug expenditures and projections for 2021, American Journal of Health-System Pharmacy, Volume 78, Issue 14, 15 July 2021, Pages 12941308

74. Wagner EH, Sandhu N, Newton KM, McCulloch DK, Ramsey SD, Grothaus LC. Effect of improved 

Prescribed Prescription and Non-Prescription Drugs in the United States Provide Economic Value"

glycemic control on health care costs and utilization. JAMA. 2001;285(2):182-189.

75. Wang G, Zhang Z, Ayala C, Dunet DO, Fang J, George MG. Costs of hospitalization for stroke patients aged 18-64 years in the United States. J Stroke Cerebrovasc Dis. 2014 May-Jun;23(5):8618 .

76. Watt JA, Goodarzi Z, Veroniki AA, Nincic V, Khan PA, Ghassemi, M, Comparative efficacy of interventions for aggressive and agitated behaviors in dementia, Ann Internal Med, 2019, Oct

77. WebMD, Diabetes, WebMD, 2019.

78. WebMD, What you need to know about Antibiotic resistance, 2020.

79. WebMD, Plavix oral: Uses, side effects, interactions, pictures, warnings \& dosing. Retrieved March 02, 2021.

80. Wells GA, Cranney A, Peterson J, Boucher M, Shea B, Welch V, Coyle D, Tugwell P, Etidonate for the primary and secondary prevention of osteoporotic fractures in postmenopausal women, Cochrane Database of Systemic Reviews 2008, Issue 1.

81. Westra H, The Effectiveness of Psychotherapy, What the research tells us, find a psychologist, 2010.

82. Wilkinson M, Lies, Damn Lies, and Prescriptions, mjacksonw.com, 2015, November 6

83. Zhuo X, Zhang P, Hoerger TJ. Lifetime direct medical costs of treating type 2 diabetes and diabetic complications. Am J Prev Med, 2013, Sep; 45(3):253-61.

84. Zuzana, M., \& Kala, P. (n.d.). Benefits and risks of clopidogrel use in patients with coronary artery disease: Evidence from randomized studies and registries, Clin Ther, 2008, 30, 2:2191-202. 